\title{
Statistical Analysis of the Government Expenditure for Greece: January 2008- September
}

\author{
Juxhen Duzha \\ University of New York Tirana, Albania \\ Brunilda Hoxhalli \\ University of New York Tirana, Albania \\ Enxhi Lika \\ University of Tirana, Albania \\ Steisi Mici \\ University of New York Tirana, Albania
}

\begin{abstract}
The main purpose of the present study is to develop a statistical analysis of the government expenditure for Greece during the period January 2008- September 2015. The source of the official data is the Greece Organization for Economic Co-operation and Development. The Kolmogorov's Central Limit Theorem, "fair game" concept in the sense of Stein-Vorobiev, Kolmogorov- Smirnov- Lilliefors test and Shapiro- Wilk test are applied. The government expenditure is estimated based on current price or as a percentage of GDP. Some results of the present study include: The official data of quarterly government expenditure for Greece during the period January 2008-September 2015 contradicts the CLT at the confidence level 95\%. The official data of quarterly government expenditure expressed as a fraction of GDP for Greece during the period January 2008September 2015 contradicts CLT at the confidence level 95\%. The government expenditure process in Greece during the period January 2008-September 2015 is an unfair game at the confidence level $95 \%$. The government expenditure as a fraction of GDP in Greece during the period January 2008-September 2015 is an unfair game at the confidence level $95 \%$. The official data of quarterly GDP for Greece during the specified period contradicts CLT at the confidence level $95 \%$. The quarterly GDP in Greece during the specified period is a fair game at the confidence level $95 \%$.
\end{abstract}

Keywords: government expenditure, GDP, CLT, fair game, OECD, Greece.

\section{Abbreviations}

CLT- Central Limit Theorem

GDP- Gross Domestic Product

KSL- Kolmogorov-Smirnov-Lilliefors

SW- Shapiro-Wilk

OECD- Organisation for Economic Co-operation and Development

\section{Introduction}

The main purpose of this study is to develop a statistical analysis of the quarterly government expenditure for Greece during the period January 2008 - September 2015. The source of the official data is the Organization for Economic Co-operation and Development (OECD). 


\section{Definition 1}

\section{Government expenditure for a given country during a specified period of time is the market value of government purchases of goods and services.}

Government expenditure includes government purchases of goods and services produced domestically or abroad. For the purpose of GDP accounts, government expenditure excludes transfer payments (for example, Social Security payments to retirees) and also excludes interest paid on government debt. These categories are omitted because they represent payments to other agents in the economy, who will use those payments to buy goods and services. To avoid doublecounting, these government payments to other agents are not counted as government expenditure on goods and services.

According to the Keynesian Theory, increased government expenditure raises aggregate demand and increases consumption, which leads to increase production and faster recovery from recessions. Classical economists, on the other hand, believe that increased government expenditure exacerbates an economic contraction by shifting resources from the private sector, which they consider productive, to the public sector, which they consider unproductive, see Blanchard (2011), Mankiw (2011).

Government expenditure is a component of the GDP formula:

$\mathrm{GDP}=\mathrm{C}+\mathrm{I}+\mathrm{G}+\mathrm{X}-\mathrm{M}$,

where $\mathrm{C}$ denotes consumption, I denotes investments, $\mathrm{G}$ denotes government expenditure, $\mathrm{X}$ denotes exports, and $\mathrm{M}$ denotes imports. GDP represents gross domestic product.

GDP is the market value of all officially recognized final goods and services produced within a country in a given period of time (quarterly GDP versus annual GDP), Blanchard (2011) and Mankiw (2011).

GDP can be determined in three ways, all of which should, in principle, give the same result:

-Production Approach

-Expenditure Approach

-Income Approach

In the present study it is applied the Expenditure Approach.

The government expenditure for Greece is expressed in Euro or as a fraction of GDP, called GDP share.

The rest of the paper is organized as follows:

Section 2 contains the methodology of the research

Section 3 provides the dynamics of quarterly government expenditure

Section 4 presents the investigation of fair game hypothesis for government expenditure

Section 5 provides the dynamics of quarterly GDP process

Section 6 concludes the paper

\section{Methodology}

Theoretical approach of the present study contains CLT, Martingale Theory and Hypothesis Testing, especially for fair game hypothesis in the sense of Stein - Vorobiev.

The GDP formula (or National Income Accounting Identity) confirms that the market value of domestic production is equal to total expenditure of domestic economic agents $(C+1+G)$, plus the expenditure of foreign agents on exports $(X)$ minus the value of domestic expenditure that was imported (M).

Government expenditure in Greece occurs in several levels of government, including primarily central and local governments. 
Changes in government expenditure are a major component of fiscal policy, used to stabilize the macroeconomic business cycle.

The Central Limit Theorem (CLT) explains why many probability distributions tend to be very close to the normal distribution. The CLT is also known as the second fundamental theorem of Probability Theory. The Law of Large Numbers is the first fundamental theorem, and the Law of the Iterated Logarithm is the third fundamental theorem of Probability Theory. The Law of the Iterated Logarithm tells us what is happening "in between" The Law of Large Numbers and The CLT. Specifically, it says that the normalizing function $\sqrt{n l_{n}\left(l_{n} n\right)}$, intermediate in size between $\mathrm{n}$ of The Law of Large Numbers and $\sqrt{n}$ of The CLT, provides a nontrivial limiting behavior, see Shiryaev (2006). A contemporary version of the CLT is given by A.N.Kolmogorov.

\section{Theorem 1 (CLT)}

If all random samples $\left(x_{1}, x_{2}, \ldots, x_{n}\right)$ of a reasonably large size $\mathrm{n}>30$ are selected from any random variable (population) $\mathrm{X}$ with finite expectation $\mu$ and variance $\sigma^{2}$ then the probability distribution of the sample mean $\bar{x}$ is approximately normal with expectation $\mu$ and variance $\frac{\sigma 2}{n}$. This approximation improves with larger samples, as $n \rightarrow \infty$, see Kolmogorov (2002).

\section{Theorem 2 (Berry - Esséen)}

If the third central moment $E(X-\mu)^{3}$ exists and is finite, then the above convergence is uniform for all $x \in(-\infty,+\infty)$ and the speed of convergence is at least on the order $\frac{1}{\sqrt{n}}$, see Shiryaev (2006).

\section{Theorem 3 (Arstein - Ball - Barthe - Naor)}

The convergence to normal distribution is monotonic in the sense that the entropy of the random variable

$$
Z_{n}=\frac{n(\bar{x}-\mu)}{\sigma \sqrt{n}}
$$

increases monotonically to that of the standard normal distribution (Arstein, Ball, Barthe, and Naor, 2004).

The amazing and counterintuitive thing about CLT is that no matter what the probability distribution of the parent population $\mathrm{X}$, the probability distribution of the sample mean $\bar{x}$ approaches a normal curve.

\section{Theorem 1}

If a stochastic process $X(t)$ is $F_{t}^{0}$-martingale, then $E[X(t)]=$ constant, $\forall t \in \mathrm{N}$.

\section{Theorem 2}

If a stochastic process is not $F_{t}^{0}$-martingale, then it is not also $F_{t}$-martingale.

\section{Theorem 3}

The stochastic process $\{X(t)\}, t \in \mathrm{N}$, is a $F_{t}^{0}$-martingale if and only if the process

$$
\{Z(t)=X(t)-X(t-1)\}, t \geq 2,
$$

is a fair game. That is, $Z(t)$ follows normal distribution and

$$
E\left[Z(t) \mid F_{t-1}^{0}\right]=E[Z(2)]=0 \quad, \forall t \geq 3 \text {. }
$$

The definition of fair game was given by J. Stein (1974), Nobel Award Winner in Economic Sciences and by Vorobiev (1974), Professor of Mathematics at Moscow University. 
"Unfair game" in the sense of Stein -Vorobiev means "speculative game".

In most applications where we wish to test for normality, the population mean $\mu$ and variance $\sigma^{2}$ are unknown. In order to perform the Kolmogorov-Smirnov test, we must assume that $\mu$ and $\sigma^{2}$ are known. The Lilliefors test, which is quite similar to the Kolmogorov - Smirnov test, overcomes this problem. The major difference between the two tests is that, with the Lilliefors test, the sample mean $\bar{x}$ and the sample standard deviation s are used (instead of $\mu$ and $\sigma$ ) to calculate the cumulative distribution function $F(x)$. The sample cumulative function $S(x)$ and the test statistic

$$
D=\max _{i}\left|F\left(x_{i}\right)-S\left(x_{i}\right)\right|
$$

are both computed as in the Kolmogorov - Smirnov test. In the Lilliefors test we compare the computed value $D$ with the critical value $D_{c}$ provided by the table of the Lilliefors test.

The SW test for normality compares a set of sample data $\left(x_{1}, x_{2}, \ldots, x_{n}\right)$ against the normal distribution. The SW test for normality is a very powerful test. This test is of regression type and assesses how well the observed cumulative frequency distribution curve fits the expected normal cumulative curve. The SW test for normality is sensitive to both skewness and kurtosis. In general, SW test is more accurate that KSL test, Cramer - Von Mises test, Durbin test, Chi-squared test, and $b_{1}$ test. (Wackearley, Mendenhall, and Schaeffer 2007, Hogg 2009, Field 2013). We use SPSS version 22.

\section{Dynamics of quarterly government expenditure}

The data set is quarterly government expenditure expressed in thousands of Euro during the period January 2008September 2015, see table 1 in Appendix. Using SPSS (version 22, 2014), compute the statistical parameters for the data.

\begin{tabular}{|c|c|c|c|c|}
\hline & & & Statistic & Std. Error \\
\hline GOVEXP & $\begin{array}{l}\text { Mean } \\
95 \% \text { Confidence Interval for Mean } \\
5 \% \text { Trimmed Mean } \\
\text { Median } \\
\text { Variance } \\
\text { Std. Deviation } \\
\text { Minimum } \\
\text { Maximum } \\
\text { Range } \\
\text { Interquartile Range } \\
\text { Skewness } \\
\text { Kurtosis }\end{array}$ & $\begin{array}{l}\text { Lower Bound } \\
\text { Upper Bound }\end{array}$ & $\begin{array}{l}10956.406250 \\
10300.430459 \\
11612.382041 \\
10906.583333 \\
11034.500000 \\
3310338.894 \\
1819.4336740 \\
8791.0000 \\
14067.0000 \\
5276.0000 \\
3608.7500 \\
233 \\
-1.404\end{array}$ & $\begin{array}{r}.414 \\
.809\end{array}$ \\
\hline
\end{tabular}

\section{Tests of Normality}

\begin{tabular}{|l|l|l|l|l|l|l|}
\hline \multirow{2}{*}{} & \multicolumn{4}{l|}{ Kolmogorov-Smirnova } & \multicolumn{3}{l|}{ Shapiro-Wilk } \\
\cline { 2 - 7 } & Statistic & Df & Sig. & Statistic & df & Sig. \\
\hline GOVEXP & .161 & 32 & .035 & .895 & 32 & .005 \\
\hline
\end{tabular}

a. Lilliefors Significance Correction 
Test the hypothesis:

$\mathrm{H}_{0}$ : The quarterly government expenditure for Greece during the period January 2008-September 2015 follow a normal distribution.

$H_{1}$ : The quarterly government expenditure for Greece during the period January 2008-September 2015 follow a non-normal distribution.

Using SPSS, find the significance level $p=0.035$ for KSL test and $p=0.005$ for SW test.

Decision Rule:

$\mathrm{P}<\mathrm{a}=0.05$ in both cases. Therefore, reject the null hypothesis $\mathrm{H}_{0}$ at the confidence level $95 \%$.

In other words, the official data of quarterly government expenditure for Greece during the period January 2008-September 2015 contradicts CLT at the confidence level 95\%.

-The data set is quarterly government expenditure expressed as a fraction of GDP for Greece during the period January 2008-September 2015. Using SPSS (version 22, 2014), compute the statistical parameters for the data.

Descriptives

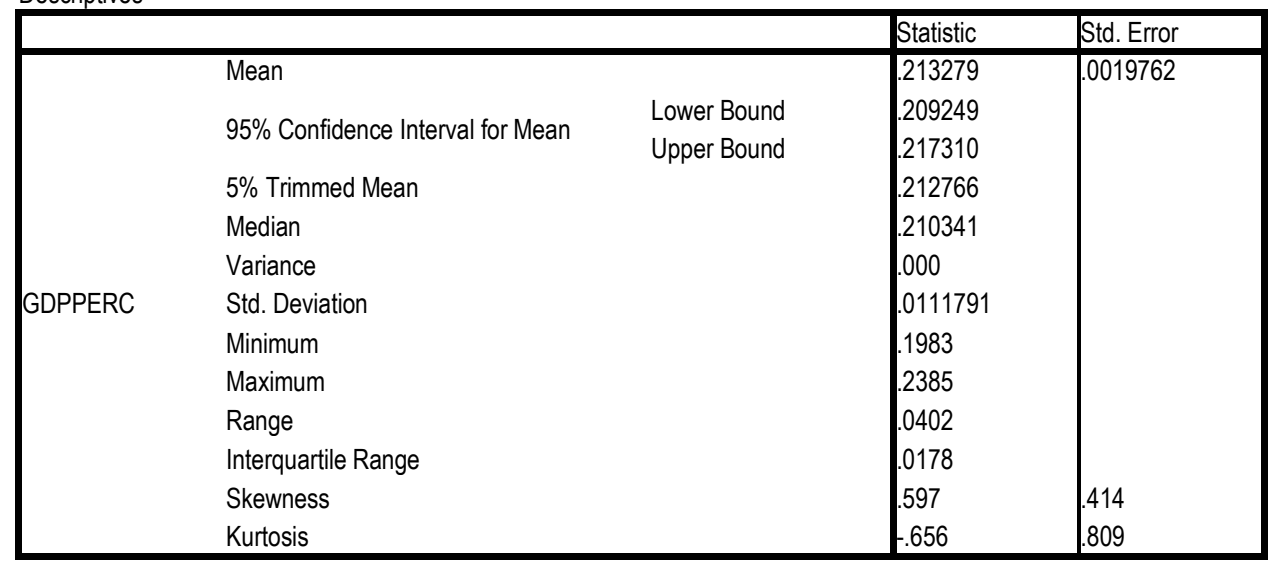

Tests of Normality

\begin{tabular}{|c|c|c|c|c|c|c|}
\hline & Kolmogo & & & Shapiro- & & \\
\hline & Statistic & Df & Sig. & Statistic & df & Sig. \\
\hline GDPPERC & 153 & 32 & .054 & .928 & 32 & .035 \\
\hline
\end{tabular}

a. Lilliefors Significance Correction

Test the hypothesis:

$\mathrm{H}_{0}$ : The quarterly government expenditure for Greece during the period January 2008-September 2015 follow a normal distribution.

$\mathrm{H}_{1}$ : The quarterly government expenditure for Greece during the period January 2008-September 2015 follow a non-normal distribution.

Using SPSS, find the significance level $p=0.054$ for KSL test and $p=0.035$ for SW test.

Decision Rule:

$\mathrm{P}<\mathrm{a}=0.05$ in both cases. Therefore, reject the null hypothesis $\mathrm{H}_{0}$ at the confidence level $95 \%$. 
In other words, the official data of quarterly government expenditure expressed as a fraction of GDP for Greece during the period January 2008-September 2015 contradicts CLT at the confidence level 95\%.

\section{The investigation of fair game hypothesis for government expenditure}

-The data set is the successive differences in thousands of Euro of quarterly government expenditure for Greece during the period January 2008-September 2015. Using SPSS (version 22, 2014), compute the statistical parameters for the data.

Descriptives

\begin{tabular}{|c|c|c|c|c|}
\hline & & & Statistic & Std. Error \\
\hline FDIFFGOVEXP & $\begin{array}{l}\text { Mean } \\
\text { 95\% Confidence Interval for Mean } \\
5 \% \text { Trimmed Mean } \\
\text { Median } \\
\text { Variance } \\
\text { Std. Deviation } \\
\text { Minimum } \\
\text { Maximum } \\
\text { Range } \\
\text { Interquartile Range } \\
\text { Skewness } \\
\text { Kurtosis }\end{array}$ & $\begin{array}{l}\text { Lower Bound } \\
\text { Upper Bound }\end{array}$ & $\begin{array}{l}-111.161290 \\
-248.345013 \\
26.022432 \\
-126.917563 \\
-80.000000 \\
139874.806 \\
373.9984043 \\
-798.0000 \\
1146.0000 \\
1944.0000 \\
504.0000 \\
794 \\
3.196\end{array}$ & $\begin{array}{l}. \\
.421 \\
.821\end{array}$ \\
\hline
\end{tabular}

Tests of Normality

\begin{tabular}{|l|l|l|l|l|l|l|}
\hline & \multicolumn{4}{l}{ Kolmogorov-Smirnova } & Shapiro-Wilk \\
\cline { 2 - 7 } & Statistic & df & Sig. & Statistic & df & Sig. \\
\hline FDIFFGOVEXP & 128 & 31 & $200^{*}$ & .910 & 31 & .013 \\
\hline
\end{tabular}

Using KSL test as well as SW test for normality we test the hypothesis:

$H_{0}$ : The successive differences of the quarterly government expenditures in thousands of Euro in Greece over the specified period follow a normal distribution.

$H_{1}$ : The successive differences of the quarterly government expenditures in thousands of Euro in Greece over the specified period follow a non- normal distribution.

We apply the KSL test as well as the SW test for normality Using SPPS (2014) we find the computed value of KSL test= .128 and associated significance level $=.200$. The computed value of SW statistics is .910 , which corresponds to a significance level of .013 .

Decision Rule: Reject the null hypothesis $H_{0}$ at the confidence level 95\%. In other words, the government expenditure process in Greece during the period January 2008-September 2015 is an unfair game at the confidence level 95\%.

--The data set is the successive differences of quarterly government expenditure as a fraction of GDP for Greece during the period January 2008-September 2015.

Using SPSS (version 22, 2014), compute the statistical parameters for the data.

Descriptives

\begin{tabular}{|c|c|c|c|c|}
\hline & & & Statistic & Std. Error \\
\hline \multirow{2}{*}{ FDIFFGDPPERC } & Mean & & -.000025 & .0011787 \\
\hline & 95\% Confidence Interval for Mean & Lower Bound & -.002432 & \\
\hline
\end{tabular}




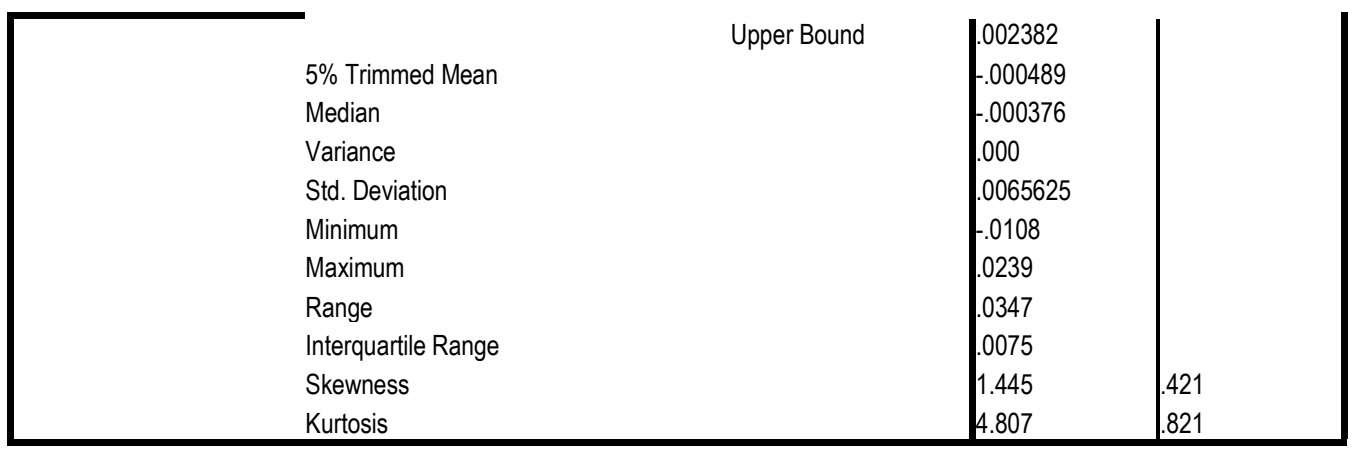

Tests of Normality

\begin{tabular}{|l|l|l|l|l|l|l|}
\hline & \multicolumn{4}{l|}{ Kolmogorov-Smirnova } & Shapiro-Wilk & \\
\cline { 2 - 7 } & Statistic & df & Sig. & Statistic & df & Sig. \\
\hline FDIFFGDPPERC & 109 & 31 & $.200^{*}$ & .897 & 31 & .006 \\
\hline
\end{tabular}

Using KSL test as well as SW test for normality we test the hypothesis:

$H_{0}$ : The successive differences of quarterly government expenditure as a fraction of GDP in Greece over the specified period follow a normal distribution.

$H_{1}$ : The successive differences of quarterly government expenditure as a fraction of GDP in Greece over the specified period follow a non- normal distribution.

We apply the KSL test as well as the SW test for normality Using SPPS (2014) we find the computed value of KSL test= .109 and associated significance level= .200 . The computed value of SW statistics is .897 , which corresponds to a significance level of .006 .

Decision Rule:

Reject the null hypothesis $H_{0}$ at the confidence level $95 \%$. In other words, the government expenditure as a fraction of GDP in Greece during the period January 2008-September 2015 is an unfair game at the confidence level 95\%.

\section{The dynamics of quarterly GDP process}

The data set is quarterly GDP in thousands of Euro during the period January 2008-September 2015. Using SPSS (version 22, 2014), compute the statistical parameters for the data.

Descriptives

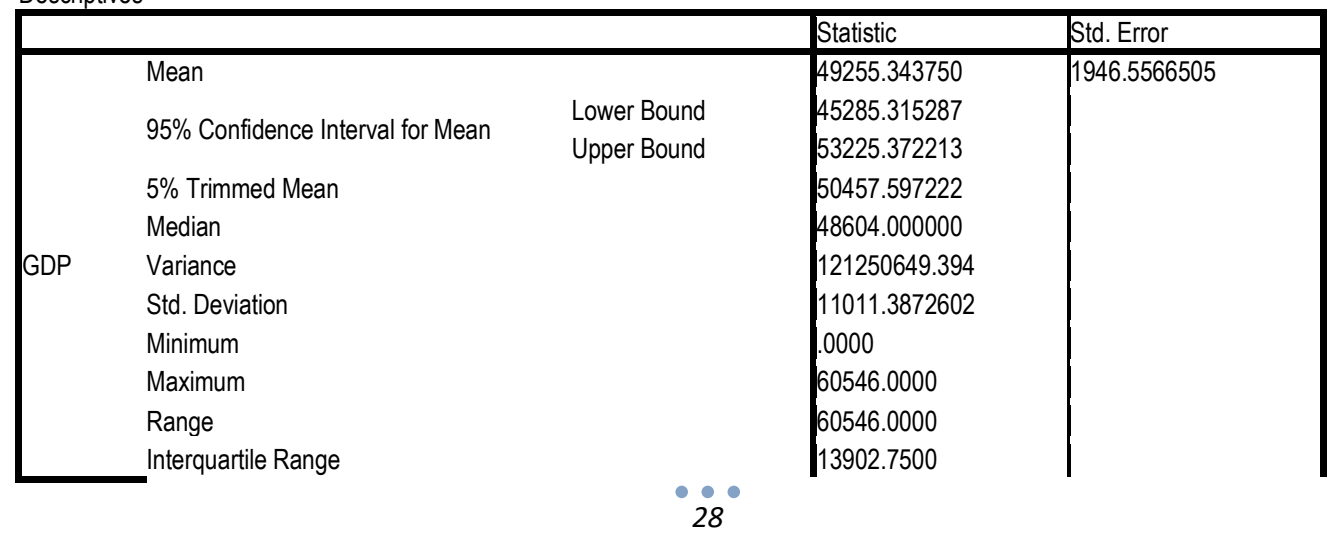




\begin{tabular}{|l|l|l|}
\hline Skewness & -2.857 & .414 \\
Kurtosis & 12.654 & .809 \\
\hline
\end{tabular}

Tests of Normality

\begin{tabular}{|l|l|l|l|l|l|l|}
\hline \multirow{3}{*}{} & \multicolumn{5}{|l|}{ Kolmogorov-Smirnova } & Shapiro-Wilk \\
\cline { 2 - 7 } & Statistic & df & Sig. & Statistic & df & Sig. \\
\hline GDP & 273 & 32 & .000 & .691 & 32 & .000 \\
\hline
\end{tabular}

Test the hypothesis:

$\mathrm{H}_{0}$ : The quarterly GDP for Greece during the period January 2008-September 2015 follow a normal distribution.

$H_{1}$ : The quarterly GDP for Greece during the period January 2008-September 2015 follow a non-normal distribution.

Using SPSS, find the significance level $p=0.000$ for KSL test and $p=0.000$ for SW test.

Decision rule:

$\mathrm{P}<\mathrm{a}=0.05$ in both cases. Therefore, reject the null hypothesis $\mathrm{H}_{0}$ at the confidence level $95 \%$.

In other words, the official data of quarterly GDP for Greece during the period January 2008-September 2015 contradicts CLT at the confidence level $95 \%$.

--The data set is the successive differences of quarterly GDP in thousands of Euro for Greece during the period January 2008-September 2015. Using SPSS (version 22, 2014), compute the statistical parameters for the data.

Descriptives

\begin{tabular}{|c|c|c|c|c|}
\hline & & & Statistic & Std. Error \\
\hline FDIFFGDP & $\begin{array}{l}\text { Mean } \\
95 \% \text { Confidence Interval for Mean } \\
5 \% \text { Trimmed Mean } \\
\text { Median } \\
\text { Variance } \\
\text { Std. Deviation } \\
\text { Minimum } \\
\text { Maximum } \\
\text { Range } \\
\text { Interquartile Range } \\
\text { Skewness } \\
\text { Kurtosis }\end{array}$ & $\begin{array}{l}\text { Lower Bound } \\
\text { Upper Bound }\end{array}$ & $\begin{array}{l}-543.838710 \\
-829.807468 \\
-257.869951 \\
-591.964158 \\
-642.000000 \\
607815.140 \\
779.6249995 \\
-1695.0000 \\
1728.0000 \\
3423.0000 \\
1093.0000 \\
896 \\
1.110\end{array}$ & $\begin{array}{r}.421 \\
.821\end{array}$ \\
\hline
\end{tabular}

\section{Tests of Normality}

\begin{tabular}{|l|l|l|l|l|l|l|}
\hline \multirow{2}{*}{} & \multicolumn{4}{l|}{ Kolmogorov-Smirnova } & \multicolumn{3}{l|}{ Shapiro-Wilk } \\
\cline { 2 - 7 } & Statistic & df & Sig. & Statistic & df & Sig. \\
\hline FDIFFGDP & .148 & 31 & .083 & .944 & 31 & .107 \\
\hline
\end{tabular}

Using KSL test as well as SW test for normality we test the hypothesis: 
$H_{0}$ : The successive differences of the quarterly GDP in thousands of Euro in Greece over the specified period follow a normal distribution.

$H_{1}$ : The successive differences of the quarterly GDP in thousands of Euro in Greece over the specified period follow a non- normal distribution.

We apply the KSL test as well as the SW test for normality Using SPPS (2014) we find the computed value of KSL test= .148 and associated significance level= .083 . The computed value of SW statistics is .944 , which corresponds to a significance level of .107.

Decision Rule: Accept the null hypothesis $H_{0}$ at the confidence level 95\%. In other words, the quarterly GDP in Greece during the period January 2008-September 2015 is a fair game at the confidence level $95 \%$.

\section{Conclusion}

In the present study developed a statistical analysis of the quarterly government expenditure for Greece during the period January 2008-September 2015. The source of the official data is OECD. The government expenditure is estimated based on current price or as a fraction of GDP.

Using Kolmogorov's CLT and the "fair game" concept in Stein-Vorobiev sense, are obtained the following results:

The official data of quarterly government expenditure for Greece during the period January 2008-September 2015 contradicts the CLT at the confidence level $95 \%$.

The official data of quarterly government expenditure expressed as a fraction of GDP for Greece during the period January 2008-September 2015 contradicts CLT at the confidence level 95\%.

The government expenditure process in Greece during the period January 2008-September 2015 is an unfair game at the confidence level $95 \%$.

The government expenditure as a fraction of GDP in Greece during the period January 2008-September 2015 is an unfair game at the confidence level $95 \%$.

The official data of quarterly GDP for Greece during the specified period contradicts CLT at the confidence level 95\%.

The quarterly GDP in Greece during the specified period is a fair game at the confidence level $95 \%$.

The mean of the quarterly government expenditure as a fraction of GDP in Greece during the period January 2008September 2015 is $21.32 \%$, the maximum value is $23.85 \%$ and the minimum value $19.83 \%$.

The severity of unfair game government expenditure in Greece during the specified period is an obvious feature of the present study.

These results are important for Greece Government and especially for its citizens.

\section{References}

[1] Acemoglu, D., Laibson, D. and List, J.A. (2016) Macroeconomics, Pearson, USA.

[2] Blanchard, O. (2011). Macroeconomics, Pearson, USA.

[3] Bureau of Economic Analysis (2016). Financial Times Articles \& Analysis.

[4] Field, A. (2013). Discovering Statistics Using SPSS (4ed.), London: Sage.

[5] Hogg, R. V. (2009). Probability and Statistical Inference, 8ed., Prentice Hall.

[6] Kolmogorov, A. N. (2002). Probability Theory, Moscow: Nauka.

[7] Mankiw, N. Gregory (2011). Macroeconomics, $8^{\text {th }}$ edition, New York: Work Publishers. 
[8] Shiryaev, A. N. (2006). Probability, second edition, Springer, New York.

[9] Stein, J. L. (1974). Unemployment, inflation and monetarism. American Economic Review, 92 (5), pp 721-756.

[10] Vorobiev, N. N. (1974). Sovremennoe sostojanie teorii igr, Uspehi Matematiçeskih Nauk, 44(1), 73-98

[11] Wackearly, D. D., Mendenhall, W. and Scheaffer, R. L. (2007). Mathematical Statistics with Application Duxbury Advanced Series

\section{Appendix, Table 1:}

Table 1. Quarterly Government expenditure, quarterly GDP, and their successive

differences for Greece during the specified period January 2008-September 2015.

GDP FIDIFFGDP GovExp FDIFFGOVEXP GDPPERC FIDDPERCGDP

\begin{tabular}{|c|c|c|c|c|c|c|c|}
\hline & Q1 & 60,468 & & 12,237 & & 0.202372 & \\
\hline & Q2 & 60,546 & 78 & 12,452 & 215 & 0.205662 & 0.00329 \\
\hline \multirow[t]{4}{*}{2008} & Q3 & 61,162 & 616 & 12,716 & 264 & 0.207906 & 0.002244 \\
\hline & Q4 & 59,467 & $-1,695$ & 12,760 & 44 & 0.214573 & 0.006667 \\
\hline & Q1 & 58,306 & $-1,161$ & 13,906 & 1,146 & 0.2385 & 0.023928 \\
\hline & Q2 & 60,034 & 1,728 & 14,067 & 161 & 0.234317 & -0.00418 \\
\hline \multirow[t]{4}{*}{2009} & Q3 & 59,453 & -581 & 13,848 & -219 & 0.232923 & -0.00139 \\
\hline & Q4 & 59,907 & 454 & 13,453 & -395 & 0.224565 & -0.00836 \\
\hline & Q1 & 58,712 & $-1,195$ & 13,351 & -102 & 0.227398 & 0.002833 \\
\hline & Q2 & 57,293 & $-1,419$ & 12,627 & -724 & 0.220393 & -0.007 \\
\hline \multirow[t]{4}{*}{2010} & Q3 & 55,791 & $-1,502$ & 12,142 & -485 & 0.217634 & -0.00276 \\
\hline & Q4 & 54,900 & -891 & 12,008 & -134 & 0.218725 & 0.001091 \\
\hline & Q1 & 53,323 & $-1,577$ & 11,210 & -798 & 0.210228 & -0.0085 \\
\hline & Q2 & 52,392 & -931 & 11,364 & 154 & 0.216903 & 0.006675 \\
\hline \multirow[t]{4}{*}{2011} & Q3 & 51,479 & -913 & 11,575 & 211 & 0.224849 & 0.007946 \\
\hline & Q4 & 49,903 & $-1,576$ & 11,001 & -574 & 0.220448 & -0.0044 \\
\hline & Q1 & 49,197 & -706 & 11,068 & 67 & 0.224973 & 0.004525 \\
\hline & Q2 & 48,011 & $-1,186$ & 10,621 & -447 & 0.22122 & -0.00375 \\
\hline \multirow[t]{4}{*}{2012} & Q3 & 47,369 & -642 & 9,969 & -652 & 0.210454 & -0.01077 \\
\hline & Q4 & 46,820 & -549 & 10,078 & 109 & 0.21525 & 0.004796 \\
\hline & Q1 & 45,964 & -856 & 9,517 & -561 & 0.207053 & -0.0082 \\
\hline & Q2 & 45,360 & -604 & 9,312 & -205 & 0.205291 & -0.00176 \\
\hline \multirow[t]{2}{*}{2013} & Q3 & 44,683 & -677 & 9,241 & -71 & 0.206812 & 0.001521 \\
\hline & Q4 & 44,092 & -591 & 9,027 & -214 & 0.204731 & -0.00208 \\
\hline \multirow[t]{4}{*}{2014} & Q1 & 44,078 & -14 & 8,945 & -82 & 0.202936 & -0.0018 \\
\hline & Q2 & 44,010 & -68 & 8,955 & 10 & 0.203476 & 0.000541 \\
\hline & Q3 & 44,903 & 893 & 8,903 & -52 & 0.198272 & -0.0052 \\
\hline & Q4 & 44,149 & -754 & 8,823 & -80 & 0.199846 & 0.001574 \\
\hline \multirow[t]{2}{*}{2015} & Q1 & 44,078 & -71 & 8,957 & 134 & 0.203208 & 0.003362 \\
\hline & \multicolumn{7}{|c|}{31} \\
\hline
\end{tabular}




$\begin{array}{lllllll}\text { Q2 } & 44,153 & 75 & 8,851 & -106 & 0.200462 & -0.00275 \\ \text { Q3 } & 43,721 & -432 & 8,830 & -21 & 0.201962 & 0.0015 \\ \text { Q4 } & 43,609 & -112 & 8,791 & -39 & 0.201587 & -0.00038\end{array}$

